EESTI NSV TEADUSTE AKADEEMIA TOIMETISED. XV KÖDE FUUSIKA-MATEMAATIKA-JA TEHNIKATEADUSTE SEERIA. 1966, NR. 4

ИЗВЕСТИЯ АКАДЕМИИ НАУК ЭСТОНСКОИ ССР. ТОМ ХV СЕРИЯ ФИЗИКО-МАТЕМАТИЧЕСКИХ И ТЕХНИЧЕСКИХ НАУК. 1966, № 4

\title{
A. KIPPER
}

\section{KOSMILISEST MAGNETO-HÜDRODUNAAMIKAST*}

On huvitav märkida, et nii mõnigi füüsika probleem, mis tänapäeval paelub teadlaste tähelepanu oma võimalustega tehnilisteks rakendusteks, pärineb astrofüüsikast. Uheks sellelaadiliseks näiteks on magneto-hüdrodünaamika, mille teoreetiline ja eksperimentaalne uurimine on aktuaalne seoses aatomienergia rahumeelse kasutamisega, samuti teiste tehniliste rakenduste seisukohalt, milledest nimetamisväärsem on soojusenergia otsene elektrienergiaks muutmise perspektiiv.

Magneto-hüdrodünaamika on teadusala, mis uurib elektromagnetilise välja seaduspärasusi elektrit juhtivas vedelas või gaasilises keskkonnas ja samaaegselt selgitab vedeliku või gaasi liikumisi selle elektromagnetilise välja toimel. Magneto-hüdrodünaamika seaduste kujunemise füüsikaline põhjus seisneb elektromagnetilise välja ja elektrit juhtiva keskkonna vastastikuses mõjus ja energiavahetuses. Kosmilises magneto-hüdrodünaamikas lisanduvad eelnimetatule kosmilised mõotmed, mis tingivad nii mõnegi omapära, võrreldes laboratoorse magneto-hüdrodünaamikaga.

Huvi magnetiliste nähtuste vastu astronoomias ärkas käesoleva sajandi algul pärast magnetvälja avastamist Päikesel ja Päikese laikudes. Tuginedes Zeemanni efektile, mille kohaselt mõned spektrijooned välise magnetvälja mõjutusel lagunevad üksikuiks komponentideks, mõõdeti Päikese laikude kuni mitme tuhande örstedi tugevusi magnetvälju. Eksperimendi tehnika viimistlemine avas tee ka tähtede magnetväljade mõõtmiseks. Käesolevaks ajaks on avastatud üle paarisaja kinnistähe magnetväljadega kuni mõnituhat örstedi. Neid tähti on hakatud nimetama tähtedeks-magnetiteks. Teoreetilised kaalutlused lubavad arvata, et ka Linnutee kui tähesüsteem tervikuna omab magnetvälja. See ruumiliselt eriti ulatuslik magnetväli on aga kaunis nõrk, mitte üle $10^{-5}$ örstedi. Käesoleval ajal peetakse tõestatuks, et magnetilised tungid mängivad kosmoses ja selle arengus tähelepanuväärset osa.

Tähe või Päikese puhul on tavaks saanud eristada kahte liiki magnetvälju, mis üksteisest läbipõimunuina on tihti eristatavad ainult tinglikult. Esimest liiki nimetatakse korrapäraseks ehk tähe magnetväljaks. Selle tungjooned jooksevad siledalt, meenutavad magnetilise dipoli tungjoonte käiku ja sulguvad väljaspool tähte. Päikese üldine magnetväli on nõrk. Tuntud on Maa üldine magnetväli.

Teise liigi välju nimetatakse lokaalseteks. Tungjooned sulguvad siin märksa väiksemas ruumiosas kui täht või Päike tervikuna. Tüüpiliste lokaalsete väljade näitena võib tuua Päikese laike. Jälgides laiguga

* Ette kantud ENSV TA Füüsika ja Matemaatikateaduste Osakonna teaduslikul sessioonil 24. juunil 1965. 
seotud magnetvälja tungjoonte pilti, vôidakse täheldada teatud korrapäratust, mis erineb dipoli tungjoone pildist. On olemas laikude rühmi, kus tungjoonte süsteem on keeruline ja korrapäratu. Veelgi kirjum on pilt lokaalsetes väljades, millede ruumilised mõõtmed on laikude omast tublisti väiksemad. Siin on tungjoonte käik niivōrd korrapäratu, et on tavaks saanud neid võrrelda täiesti sassisoleva nööri puntraga.

Kosmilise magneto-hüdrodünaamika kujunemise teiseks nurgakiviks oli india füüsiku N. Saha tähtede aine termilise ionisatsiooni teooria, mille esmajooneliseks ülesandeks oli seletada tähtede spektritüüpe ja nende kujunemist. Saha teooria järgi on tähtede aine peaaegu täieliku ionisatsiooni seisundis, koosnedes elektronide, prootonite ning teiste elementide aatomituumade segust. Füüsikud on hakanud mateeria sellist olekut nimetama plasmaks, kusjuures plasma üheks oluliseks omaduseks on suur elektrijuhtivus. Näiteks on tähe aine elektrijuhtivus ligilähedalt võrdne elavhõbeda omaga, mille tõttu elektromagnetilisest seisukohast võiksime tähte jämedas pildis võrrelda suure elavhõbedast keraga. Peaaegu täieliku ionisatsiooni tôttu on ka helendavad kosmilised gaasudud suure elektrijuhtivusega. Kui uurida tähtede, udukogude või Linnutee magnetväljade omadusi, tuleb alati arvestada nii keskkonna elektrijuhtivust kui ka selle keskkonna liikumist. Teiste sõnadega: kosmiline magneto-dünaamika on alati kosmiline magneto-hüdrodünaamika.

Esmakordselt uuris elektromagnetilisi nähtusi kompleksselt koos plasma füüsikaliste omadustega rootsi füüsik Alvén, kes pani oma töödega aluse kosmilisele magneto-hüdrodünaamikale. Tuginedes Maxwelli ja hüdrodünaamika võrrandite ühisele süsteemile, näitas Alvén teoreetiliselt nn. magneto-hüdrodünaamiliste lainete tekkimise võimalusele Päikeses ja Päikese atmosfääris. Magneto-hüdrodünaamilist lainetust tekitati hiljem ka laboratooriumis ning tulemused kinnitasid Alvéni teoreetilist ennustust. Selgus, et magneto-hüdrodünaamilised lained on midagi vahepealset harilike raadiolainete ja helilainete vahel.

Kaasajal on magneto-hüdrodünamika kasvanud üle astronoomia huvide ringi ning muutunud huvitavaks tehniliseks probleemiks. Kuid ka astronoomias eneses on magneto-hüdrodünaamika tunginud kaugemale esialgsest küsimuse asetusest. Käesolevas peatuksin neil töödel, mis tehti ja tehakse Tartu Astrofüüsika Observatooriumis. Uuritavaid probleeme saab liigitada kaheks temaatiliseks lõiguks ja nimelt:

1) kosmilise magneto-hüdrodünaamika seaduste kui statistiliste seaduste iseloomustus ja

2) tähtede magnetväljade algpõhjuste väljaselgitamine.

Asudes esimese probleemide ringi käsitlemisele, märgime kohe kosmilise magneto-hüdrodünaamika loomupärast iseärasust, mis seisneb siin esinevate ruumiliste, ajaliste ja liikumiste suurtes ehk kosmilistes mõõtmetes. See tingib möningaid laboratoorseist kogemustest erinevaid olukordi. Päikese- või tähesuurune ja elektrit hästi juhtiv tahkest ainest kera on oma suure omainduktsiooni tõttu võimeline magnetvälja ülal hoidma ilma märgatava nõrgenemiseta enam kui $10^{9}$ aastat. Tähe mateeria liikumise arvestamine vähendab tähe magnetvälja iga $10^{9}$ aastalt $10^{5}$ aastale. Vähenemine on tunduv, kuid maiste sündmuste tempoga võrreldes on $10^{5}$ aastat ikkagi küllalt pikk aeg.

Kosmilist magneto-hüdrodünaamikat on tihti sarnastatud magnetohüdrodünaamikaga elektrit ülijuhtivas keskkonnas. Tõepoolest, ülijuhtivas keskkonnas püsib kord tekitatud magnetväli väga kaua, sest teda ülalhoidvad elektrivoolud praktiliselt ei sumbu oomilise takistuse tôttu. Hüdrodünaamikas tuntud sarnasuse teooria, rakendatuna magneto-hüdro- 
dünaamikas, lubab kosmilist magneto-hüdrodünaamikat iseloomustada kui sellekohaste nähtuste kompleksi ülijuhtivas keskkonnas.

Magnetvälja piltlikuks kujutamiseks kasutatakse mõnikord tungjoonte mõistet ja kujutlust. Magnetvälja muutumisel muutub tungjoonte asetus ja tihedus ruumis. Uldjuhtivas keskkonnas on tungjooned niivõrd tugevasti seotud keskkonnaga, et on saanud tavaks nimetada neid kinnikülmunuiks keskkonna külge. Selle väljendusega tahetakse toonitada tõsiasja, et ülijuhtivas keskkonnas jääb iga massielement seotuks selle tungjoonte kimbuga, mis kunagi teda läbis. Kujutlus tungjoonte kinnikülmumisest ainesse on eriti kasulik siis, kui soovitakse magneto-hüdrodünaamilistest olukordadest anda üldist ja rohkem kvalitatiivset pilti kui täpset arvulist iseloomustust.

Nii näiteks, kui tungjooned on ainesse kinni külmunud, siis muutub vii mase seesmistel liikumistel tungjoonte pikkus, tavaliselt pikenedes. See aga tähendab enamikul juhtudel magnetilise energia kasvu, mis ilmselt toimub keskkonna liikumise energia arvel. Samal ajal toimub ka vastupidine protsess: magnetvälja iga muutus tekitab elektrivoolu. Viimane omakorda kutsub magnetväljas esile keskkonnale mõjuvaid mehhaanilisi tunge ja aine liikumise. Toimub aine liikumise energia kasv, mis ilmselt sünnib magnetilise energia arvel.

Niisiis tekitab liikuv keskkond magnetvälja kasvu aine liikumise energia arvel, muutuv magnetväli aga indutseerib aine liikumist magnetvälja energia arvel. Toimub alaline energiavahetus magnetvälja ja seesmiste liikumistega varustatud keskkonna vahel. Seejuures muudetakse, nagu igas looduslikus protsessis, osa energiast pöördumatult soojusenergiaks; see transformatsioon sünnib keskkonna liikumisega kaasuva seesmise hõõrdumise ja keskkonna oomilise takistuse toimel.

Magnetvälja ja keskkonna vastastikusel energiavahetusel kosmilistes tingimustes on selle füüsikalise süsteemi evolutsiooni kulgemisele otsustav tähtsus. Oletame näiteks, et tähe magnetväli oli mingil silmapilgul täiesti korrapärane ja meenutas dipoli välja sujuvalt kulgevate tungjoonte süsteemiga. Nagu ettekandja ühes oma töös näitas, muutub selline korrapärane tähe magnetväli keskkonna ja välja vahel toimuva energiavahetuse tõttu kiiresti täiesti korrapäratuks: sujuvalt kulgevate tungjoonte süsteem läheb sassi. Koos sellega ilmuvad keskkonna pööriselised liikumised, mis lähevad varsti üle korrapäratuteks turbulentseteks liikumisteks. Tähe magnetvälja edasisel evolutsioonil kasvab magnetvälja ja keskkonna liikumiste korrapäratus. Mõeldavaks tasakaaluks on seisund ülima korrapäratusega, mida võiks sarnastada entroopia maksimumi saavutamisega termodünaamikas.

Sassisolevate tungjoontega magnetvälja ja korrapäratute pöörlemistega aine kompleksi võiks nimetada magnetiliseks turbulentsiks, eriti siis, kui vastav korrapäratus on saavutanud ülima astme. Statistilises füüsikas on süsteemiga seotud korrapärasuste mõõduks entroopia. See viib mõttele kasutada seda väga viljakat mõistet ka magnetilise turbulentsuse uurimisel. Kahjuks pole see ilma pikemata teostatav. Ka vedelike turbulentsuse uurimisel ei saa rakendada statistilise füüsika klassikalisi meetodeid. Sama olukord kandub üle ka magnetilise turbulentsi probleemidele. Magnetilise turbulentsuse lähemal uurimisel selgus selle seaduste peaaegu täielik analoogia vedelike turbulentsete liikumiste seadustega. See asjaolu võimaldas ettekandjal esile tõsta mitmeid selliseid magnetilise turbulentsuse seadusi, milledel on otsustav osa tähtede magnetväljade kujunemisel ja arenemisel. Kokku võttes andis vastav uurimistöö tähe magnetvälja jaoks järgmise pildi. 
Täht kui magneto-hüdrodünaamiline süsteem koosneb ühelt poolt keskkonna turbulentsete liikumiste väljast ja teiselt poolt sassisolevate tungjoontega magnetväljast. Kogu aja toimub energiavahetus magnetvälja ja turbulentsete liikumiste välja vahel. Tasakaalu korral, täpsemalt, statistilise tasakaalu korral, annab magnelväli liikumistele niisama palju energiat kui ta neilt saab. Peale kirjeldatu toimub mölemate energialiikide, s. o. magnetilise ja kineetilise energia muutumine soojusenergiaks, mis on pöördumatu ja põhjustab tähe magnetvälja pikaldase sumbumise. Kui puuduksid protsessid, mis kataksid soojusenergia näol tekkiva kao, kustuks tähe magnetväli $10^{5}$ aasta jooksul. Kosmilises ajaskaalas on see aga liialt lühike tähtede magnetväljade olemasolu seletamiseks. Kuid pole raske loetleda tervet rida põhjusi, mis tähtede sisemuses tekitavad tähe aine seesmisi liikumisi, annavad omapoolset lisa aine liikumise energiale ja lōppresultaadina ka omapoolset lisa magnetilise turbulentsi energiale.

Päikese magnetväli oma sassisolevate tungjoontega, arvukate pööriseliste liikumistega atmosfääris ja teiste magnetiliste nähtustega tohiks olla üheks näiteks kosmiliste mõõtmetega magnetilisest turbulentsist, mis võimaldab kontrollida teooria tõepärasust ja ennustuste paikapidavust. Uldiselt on kooskõla teooria ja vaatlusandmetega magnetilise turbulentsi valdkonnas täiesti rahuldav. Tuleb aga märkida, et statistiline teooria ei saa otseselt seletada Päikesel toimuvaid detailseid magnetilisi nähtusi, mis on seotud näiteks laikudega, nagnetilise perioodilisusega jne. Statistiline teooria opereerib esmajoones keskmiste arvude ja näitajatega, siludes sellega välja individuaalsed ja lokaalsed erinevused. Päikese laigud ja teised detailsed Päikese magnetilised moodustised on statistika vaatekohast fluktuatsioonideks.

Pöördume nüüd teise küsimuse ja nimelt tähe või Päikese magnetvälja tekkimise põhjuse vaatlemisele.

Nagu eespool korduvalt märgitud, kutsuvad tähe mateeria seesmised liikumised esile tähe magnetvälja energia ja ühtlasi kogu magnetvälja tugevuse kasvu. See protsess sarnaneb elektrivoolu genereerimisega dünamomasinas ja paljud uurijad nimetavadki seda dünamoprotsessiks. Dünamoprotsess aga, nagu teame, eeldab, et oleks olemas tähe aine seesmisi liikumisi ja algne magnetväli, mis võib olla väga nõrk. See aga, kust saab alguse dünamoprotsessi jaoks paratamatult vajalik nõrk magnetväli, on praeguseni rahuldavalt seletamata.

Toetudes vaatlusandmetele, mis viitavad seosele rotatsiooni kiiruse ja magnetvälja tugevuse vahel tähtede-magnetite juures, püstitas Blackett hüpoteesi, mille järgi iga massiivne ja roteeruv keha omab magnetvälja. Hilisem täielikuma vaatlusmaterjali läbitöötamine on aga tublisti kõigutanud usku Blacketti hüpoteesi tõepärasusse ja ka kaasaja teoreetiline füüsika ei toeta millegagi kõne all olevat hüpoteesi.

On esitatud tähtede magnetväljade tekkimise põhjuste hüpoteese, mis viitavad mitmesugustele elektrivoolu tekkimise võimalustele elektriliselt neutraalses plasmas. Sellised elektrivoolud saavad ilmuda kas kõrvalekallete tõttu lokaalsest termilisest tasakaalust või mitmest eripärasest liikumiste situatsioonist. Uhes oma uurimuses käsitleb ettekandja järgmist magnetvälja tekkimise võimalust tähtedel.

Teatavasti omavad elektronid nii mehhaanilist kui ka magnetilist momenti. Mitteroteeruvas plasmas on elektronide magnetilised momendid paigutatud kaootiliselt ja plasma ei oma resulteeruvat momenti. Roteeruvas kerakujulises plasmas on aga elektronidel kalduvus paigutuda oma spinnidega paralleelselt rotatsiooni teljega. Sellele korrastustendentsile 
töötab vastu kaootiline termiline liikumine. Resultaadina saab roteeruv plasma teatava magnetilise momendi, mis on seda suurem, mida kiirem on rotatsioon, ja seda nõrgem, mida kõrgem on temperatuur. Konkreetsed arvutused andsid tähe magnetvälja jaoks suuruse, mis on küllaldane dünamoprotsessi käivitumiseks.

Kõigi tähtede magnetväljade algpõhjusi seletada taotlevate hüpoteeside üheks ühiseks jooneks on nende suur kunstlikkus, kuna tähtede magnetväljade tekkimist seatakse ühendusse mõne küllaltki spetsiaalse ja harul. dase protsessiga. Arvan, et lisaks juba avaldatuile võib selliseid protsesse kombineerida veel terve hulga. Samal ajal aga ei saa lahti muljest, et sassisolevate tungjoonte magnetväli on omane igale normaalsele tähele ja et magnetvälja tekkimise põhjused tuginevad hoopis üldisemale loodusseadusele kui mõnele spetsiaalsele haruldasele protsessile tähtede sisemuses. Seoses selle mõttekäiguga tohiks huvi pakkuda järgmine arutlus.

Tähtede mateeria - see on plasma ja elektromagnetiline kiirgus, mis on segatud sellesse plasmasse. Kiirguse tihedus ja spektraalne jaotus allub tuntud Plancki seadusele, sest tähe sisemuse igas punktis valitseb su ures 1 äh enduses termilise tasakaalu olukord. Kiirguse footonid on esindatud kõigi sagedustega: nende hulgas esineb footone nii raadiolainete piirkonnast kui ka lainepikkustega sadu ja tuhandeid kilomeetreid. Raadio- ja üliraadiolainepikkusega elektromagnetilisel võnkumisel elektrit hästi juhtivas keskkonnas on elektromagnetilise võnkumisega vaakuumis või dielektrikumis võrreldes mitmeid omapäraseid jooni, millede selgitamine on meie probleemi lahendamise seisukohalt otsustava tähtsusega. Nii näiteks sumbuvad raadiolained lainepikkusega mōnikümmend kilomeetrit plasmas kiiresti ega suuda läbida nimetamisväärseid vahemaid. Elektromagnetiline lainetus lainepikkusega kümneid ja sadasid tuhandeid kilomeetreid peab end ülal aga hoopis teisiti. Nende lainete juures asub tegevusse tungjoonte keskkonna külge kinnikülmumise efekt. Tagajärjeks on see, et elektromagnetiliste lainete asemele tekivad plasmas magnetohüdrodünaamilised lained, viimased aga erinevad elektromagnetilisest lainetusest vaakuumis niivõrd, et me võime neid iseloomustada rohkem aeglaselt muutuva magnetväljana kui kiire elektromagnetilise võnkumisena. Niisiis on esitatud mõttekäigu kohaselt tähe või Päikese sassisolev magnetväli lihtsalt termilises tasakaalus või peaaegu termilises tasakaalus oleva kiirgusvälja kõige pikemalaineline osa.

Et sellele ideele anda kindlamat tuge ja põhjendada siit väljakasvavat hüpoteesi tähtede magnetväljade tekkimisest, pidas ettekandja vajalikuks lahendada ülesanne, mis seisneb järgmises. On antud elektromagnetiline kiirgus elektrit hästi juhtivas keskkonnas, tuleb leida selle kiirguse energiatihedus ja võimaluse korral ka spektraalne energiajaotus termilise tasakaalu korral. Teatavasti uuris kiirguse spektraalset jaotust termilises tasakaalus edukalt Planck, kes tuletas tema nimega seotud valemi. Ta käsitles probleemi eeldades, et elektromagnetiline kiirgus asetseb vaakuumis. Meie eeldame, et see kiirgus asetseb elektrit juhtivas keskkonnas, mis tingib nii mõnegi erinevuse Plancki klassikalisest probleemist.

Elektrit juhtivas keskkonnas säilitab ainult kiirguse lühilaineline osa võnkuva iseloomu ja ainult tema suhtes saame kõrvuti lainepikkusega rääkida ka kiirguse sagedusest. Pikalainelises osas on elektromagnetilise välja võnkuv iseloom kadunud ja siin on tegu ainult aeglaste ajaliste muutustega, mis ülimalt küünivad magneto-hüdrodünaamiliste lainetustega seotud ajaliste muutusteni. Hoolimata sellest, et elektrit juhtivas keskkonnas ei ole kogu lainepikkuste diapasoonis võimalik rääkida kiirguse sagedusest, oli ettekandjal ikkagi võimalik määrata kiirgusvälja 
kvandi mõistet, iseloomustades igat kvanti lainepikkusega ja mitte sagedusega. Lainepikkus on ühtlasi pilkkuse mõõduks, mille ulatuses kvandiga seotud väli oluliselt muutub.

Olles määranud kiirgusvälja kvandi mōiste, oli juba lihtsam leida energia jaotus eri lainepikkustega kvantide vahel termilises tasakaalus. Tulemuseks oli Plancki valem. Sellise tulemuseni pidigi jõudma, sest juba hoopis üldisemadki kaalutlused ütlesid seda ette. Seejuures pole aga tulemus triviaalne, sest ülipikalaineline osa ei tähenda käesoleval korral ülipikalainelist raadiokiirgust, vaid sassisolevat magnetvälja. Selle sassisoleva magnetvälja energia saame nüüd arvutada Plancki valemi abil. Untlasi näib ettekandjale, et tähtede ja Päikese magnetvälja olemasolu on leidnud oma loomuliku seletuse.

Nagu juba toonitatud, on esitatud hüpoteesi järgi tähe sassisolev magnetväli peaaegu termilises tasakaalus oleva ja tähte täitva elektromagnetilise kiirguse ülipikalaineline osa. Sellisena kuulub magnetväli iga normaalse tähe juurde, olles selle lahutamatuks osaks.

Lühilainelise kiirguse juures me ei suuda avastada fluktuatsioone, mis oleksid tingitud valguse kvandilisest iseloomust ja lokaalseist kõrvalekaldeist statistilisest tasakaalust. Kiirguse ülipikalainelises osas on olukord teistsugune. Kuna muudatused toimuvad siin aeglaselt ja kvantide tihedus on väike, paistavad fluktuatsioonid silma oma täies ulatuses. Päikese magnetvälja korrapäratu iseloom, Päikese laikude magnetväljad jne. tohiksid olla sellekohasteks näideteks.

Esitasin üldjoontes neid probleeme kosmilise magneto-hüdrodünaamikast, mida käsitletakse W. Struve nimelises Tartu Astrofüüsika Observatooriumis. Loomulikult on need probleemid esmajoones astrofüüsikalised. Kuid magneto-hüdrodünaamika on juba lakanud olemast ainult astrofüüsika eridistsipliiniks. Sellepärast hellitab ettekandja lootust, et saadud tulemused on kasulikud ka teistele täppisteadustele ja tehnikale.

Eesti NSV Teaduste Akadeemia

Fü̈̈sika ja Astronoomia Instituut

Saabus toimetusse 29. III 1966 